\title{
LA REANUDACIÓN DE FAENAS EN EL NUEVO PROCEDIMIENTO DE NEGOCIACIÓN COLECTIVA
}

[The Resumption of Work in the New Proceeding of Collective Bargaining]

\section{Pedro IrUReta URIarte*}

\section{RESUMEN}

La reanudación de faenas es una figura que, desde antiguo, ha sido recogida por la legislación laboral chilena. En el pasado, permitió que el Poder Ejecutivo la utilizara para poner término a determinados conflictos colectivos, asegurando la continuidad de ciertas empresas que se encontraban en huelga. No obstante, durante las últimas décadas esta institución no fue mayormente utilizada y terminó relegada a un evidente segundo plano (tanto en el Código del Trabajo como en la Ley de Seguridad del Estado). La reforma laboral impulsada por la Ley $\mathrm{N}^{\circ} 20.940$ (de 2016) ha redefinido el núcleo de

\section{ABSTRACT}

The resumption of work is a figure that has long been recognized by the Chilean labor legislation. In the past, it allowed the Executive branch to put an end to certain collective disputes, ensuring the continuity of certain companies that were on strike. However, in recent decades this institution was not used and ended mostly relegated to a secondary place (both in the Labor Code and in the State Security Law). The Labor Reform promoted by Law No. 20.940 (2016) has redefined the core of this institution, building a procedural action that assures the right of unions and employers to request on court the

RECIBIDO el 2 de noviembre 2016 y APROBADO el 20 de abril de 2017

* Abogado y Licenciado en Derecho por la Pontificia Universidad Católica de Chile. Doctor en Derecho por la Universidad Complutense de Madrid. Profesor Titular de Derecho del Trabajo de la Universidad Alberto Hurtado. Correo electrónico: piruret@uahurtado.cl 
esta figura, construyendo una acción procesal que le asegura a los titulares de la misma el derecho de solicitar -en sede judicial- el uso de esta herramienta como una manera lícita de poner término a un proceso de huelga.

\section{Palabras Claves}

Reanudación de faenas-Negociación colectiva - Limitaciones a la huelga. use of this tool as a legitimate way to end a strike.

\section{KEYWORDS}

Resumption of work - Collective bargaining - Restriction of strike.

Dentro de un capítulo especial dedicado a las limitaciones del derecho de huelga, la nueva ley laboral chilena ha incorporado una serie de herramientas judiciales que permiten impedir, en determinados casos, que la paralización legal ocurrida en un proceso de negociación colectiva cause un daño grave a bienes jurídicos que se consideran de mayor jerarquía que el ejercicio mismo de la huelga o del cierre temporal de la empresa. En el uso de esta herramienta legal, no se está haciendo alusión a una paralización contraria al orden público o las buenas costumbres, así como tampoco de un abuso en la abstención colectiva del trabajo. Por el contrario, aceptando el legítimo derecho a huelga o de cierre temporal, se faculta a la autoridad judicial para que, enfrentada al bien colectivo, ordene la reiniciación de las actividades y someta el proceso de negociación a un arbitraje obligatorio.

En virtud de lo anterior, el ordenamiento jurídico chileno ha consagrado en el artículo 363 del Código del Trabajo ${ }^{1}$ una institución -cuyo origen se remonta a las primeras leyes sociales- destinada a reanudar las faenas de aquellas empresas o entidades cuya paralización, atendida sus características, oportunidad o duración, causare grave daño a la salud, al medio ambiente, al abastecimiento de la población, a la economía del país o a la seguridad nacional. En este contexto, la reanudación surge del intervencionismo que

${ }^{1}$ El artículo señala expresamente que: "En caso de producirse una huelga o cierre temporal de la empresa, que por sus características, oportunidad o duración causare grave daño a la salud, al medio ambiente, al abastecimiento de bienes o servicios de la población, a la economia del pais o a la seguridad nacional, el Tribunal de Letras del Trabajo respectivo podrá decretar la reanudación de faenas, previa solicitud de parte (inciso primero). La solicitud se tramitará a través del procedimiento monitorio de los artículos 496 y siguientes, con excepción de lo señalado en el inciso primero del artículo 497. Podrán ejercer la acción de que trata este artículo tanto la o las empresas, como la Dirección del Trabajo o el o los sindicatos, según corresponda (inciso segundo). La reanudación de faenas se hará en las mismas condiciones vigentes al momento de presentar el proyecto de contrato colectivo (inciso tercero). Una vez que esté ejecutoriada, la sentencia definitiva deberá notificarse a la Dirección del Trabajo para los efectos de lo dispuesto en el artículo 390 (inciso cuarto)". 
ejerce el Estado en razón de diversos bienes jurídicos que se encuentran comprometidos en toda paralización de actividades, razón por la cual la autoridad respectiva puede preservar los intereses sociales más relevantes, respetando el derecho de las partes en la relación laboral, pero teniendo presente que su opción es la protección efectiva del bien común.

La reanudación de faenas tiene su fundamento en la salvaguarda de los intereses generales de la sociedad, lo que se traduce en la necesaria protección de los mismos, así como la promoción del bien común ${ }^{2}$. De esta manera, puede suceder que el legítimo ejercicio de un derecho provoque una perturbación, muchas veces no deseada ni prevista, que lesiona otros derechos considerados de especial resguardo. Enfrentada a esta contraposición de intereses, la ley le ha entregado a la autoridad judicial la posibilidad de implementar otras herramientas que permitan limitar los efectos de esa eventual lesión.

Es en este orden de ideas, dónde el legislador nacional incorpora la idea de la reanudación de faenas. Conceptualmente, esta figura ha sido definida como la intervención del Estado en un conflicto legal o ilegal, que envuelve a una o más empresas, en el cual ha tenido lugar una paralización o cierre temporal de actividades, que causa un daño grave al país o a sus habitantes, destinado a la reactivación inmediata de su funcionamiento por exigirlo así intereses públicos comprometidos ${ }^{3}$. Su regulación se produce en dos ámbitos claramente distintivos: el laboral y el penal. En el primer caso, la norma artículo 363 reproduce un texto muy similar al que se consagrara en otros cuerpos legales pretéritos, aun cuando modifica el sujeto habilitado para ordenar la reanudación (la Ley No 20.940 traslada la facultad desde el Presidente de la República al Juez de Letras del Trabajo). En la segunda hipótesis, la reforma laboral dejó subsistente una facultad propia del ámbito penal, y que se concentra en el artículo 38 de la Ley de Seguridad del Estado. Ambas normas apuntan al mismo objetivo, pero tienen un distinto centro de aplicación.

En el presente artículo se dilucidan las diversas variantes que abre la nueva regulación de la reanudación de faenas. Se trata de una figura muy poco estudiada en las últimas décadas, y cuya aplicación práctica fue notoriamente más intensa durante la vigencia del Código de 1931. De todas maneras, el Código la ha mantenido como un supuesto típico de limitación al ejercicio del derecho de huelga, cuestión que abre una serie de interrogantes sobre el alcance de esta nueva facultad judicial.

${ }^{2}$ Véase artículo $1^{\circ}$ de la Constitución.

3 Cfr., Macchiavello Contreras, Guido, Derecho Colectivo del Trabajo (1a edición, Santiago, Editorial Jurídica de Chile, 1989) p. 472. 


\section{I . ANTECEDENTES HistóRICOS}

La norma establecida en el actual artículo 363 del Código chileno no es nueva. Ya la Ley No 4.056 (de 1924), estableció en su artículo 51, los primeros atisbos de esta figura al disponer que: "Podrá el Gobierno, en los casos de huelga o cierre de fábricas, en empresas o servicios cuya paralización ponga en peligro inmediato la existencia, la salud de la población o la vida económico-social del pais, proceder al reemplazo de los huelguistas en la forma que lo exijan los intereses generales, previo decreto especial que indique los fundamentos de la medida". Este precepto fue el resultado de una proposición realizada por una Comisión Mixta de Diputados y Senadores, siendo el único antecedente de la normativa social aprobada en los convulsionados días de septiembre de 1924. En el informe respectivo, se señalaba que en atención a la "idiosincrasia de nuestra población obrera, llevó este acuerdo hasta rechazar el arbitraje como sistema obligatorio de solución de conflictos que surgen en una empresa o servicios de utilidad pública, a fin de evitar el quebrantamiento de la legislación social por huelgas que, a pesar de la prohibición, pudieren promoverse en esta clase de trabajos" ". En esta línea, el Informe de la Comisión autorizaba al Gobierno respectivo para que, ante situaciones de esta naturaleza, procediera a tomar todas las medidas tendientes a asegurar la continuidad de esos servicios (entre las cuales se contaba, incluso, la del reemplazo del personal en huelga $)^{5}$, toda vez que al legislador de aquella época, en que el número de paralizaciones de empresas no sobrepasaba las 150 huelgas, le parecía necesario dotar a la autoridad ejecutiva de un mecanismo que le permitiese encauzar los conflictos sociales.

${ }^{4}$ Véase, RiEsco, Germán, Alcance del Artículo 547 del Código del Trabajo. Facultad de los Tribunales para rever los actos del Ejecutivo, en RDJ. T. XLIV (1947), p. 115. El mismo autor señala que la expresión u t i l i d a d p ú b l i c a que se utilizó en la referida ley, tendría su origen en el término inglés $p u b l i c$ u $t$ ility, que comprendería a los servicios y suministros generalmente obtenidos en las grandes ciudades, como omnibus, electricidad o agua, entre otros.

${ }^{5}$ Esta referencia histórica tiene cierta vinculación con la finalidad que actualmente se les asigna a los servicios públicos de conformidad con el artículo 28 del DFL No 1/19.653, sobre Bases Generales de la Administración del Estado. En efecto, esta última norma establece que los servicios públicos son órganos administrativos encargados de satisfacer necesidades colectivas, de manera regular y continua. Pues bien, son justamente estos elementos los que caracterizan a estos entes, toda vez que priman en ellos la satisfacción de la necesidad colectiva, y la necesaria continuidad y regularidad en su actividad. Y resulta que las ideas de continuidad y regularidad, también, se encuentran insertas en los fundamentos de la reanudación de faenas. De allí que se haya sostenido que, al legislador de las primeras leyes sociales le importaba que el acceso a aquellos servicios, considerados indispensables para la sociedad, no se vieran interrumpidos. 
Como es sabido, la Ley No 4.056 fue incorporada con posterioridad en el Código del Trabajo del año 1931, el cual modificó la posibilidad del reemplazo de los trabajadores por la facultad de reanudar las faenas, eliminando de paso la referencia que se efectuaba al peligro que podía importar la paralización para la existencia de la población. De esta manera, el artículo 626 (547) del texto de 1931 consagró la reanudación de las labores al disponer que: "En los casos de huelga o cierre de fábricas, en empresas o servicios cuya paralización pusiere en peligro inmediato la salud o la vida económico-social de la población, el gobierno podrá proveer a la reanudación de las faenas en la forma que lo exijan los intereses generales, previo decreto especial que indique los fundamentos de la medida". Según lo plantearon los propios considerandos del Código de 1931, la modificación en la redacción legal sólo obedeció a la constatación de algunas deficiencias que urgía corregir, "manteniendo en su integridad los principios fundamentales" de las leyes sociales dictadas hasta entonces (considerando tercero).

Algunos comentaristas del Código de 1931 estimaron que la norma aplicada en el artículo 626 (547) no se aplicaba a cualquier empresa o servicio, sino sólo a aquellas cuya paralización pusiere en peligro inmediato la salud o vida de la población, cosa que se expresaría solamente en "las empresas fiscales y semifiscales y de servicios públicos" ". Esta interpretación, tenía su fundamento en que la norma hacía alusión a bienes jurídicos que afectaban a toda la población, y no exclusivamente a los operarios de una empresa específica. De esta manera, según la doctrina de la época, la disposición del antiguo Código del Trabajo se refería a empresas o servicios de interés público, de interés general, de los cuales no era posible prescindir sin comprometer la salud o la vida de la población, de los habitantes de una localidad o en general de los habitantes de la República. A mayor abundamiento, se agregaba que esta norma habría sido tomada de la Ley No 21, del año 1920, dictada en Colombia; y que dicho cuerpo legal consideraba entre las empresas ligadas a la seguridad, la salubridad y la vida económico-social del país a los medios de transporte (entre los cuales se destacan los ferrocarriles, tranvías, y los buques tanto fluviales como marítimos), el alumbrado público de las poblaciones, la higiene y aseo de las ciudades, así como la explotación de las minas en poder del Estado. Basado en lo anterior, la doctrina de aquél entonces concluía que el alcance de esta norma decía relación con las "empresas fiscales y de servicios de utilidad pública. Ni la cuantía de las pérdidas monetarias, ni el número de obreros cesantes permitiría al Gobierno mezclarse en negocios de otra indole"

${ }^{6}$ Véase, Riesco, cit. (n. 4), p. 115.

7 Véase Riesco, cit. (n. 4), p. 116. Como se aprecia en los ejemplos citados, 
En cuanto a la interpretación de la jurisprudencia administrativa, ésta estimó que en virtud del antiguo artículo 626 (547), la facultad del gobierno podía incluso llegar hasta lesionar, aunque transitoriamente, el derecho de propiedad de las empresas, ejercitando la administración de ellas, sin necesidad de resolución judicial ${ }^{8}$. Es decir, concebía a esta facultad de reanudación como un derecho amplio del Poder ejecutivo que incluso incursionaba en actos propios de gestión.

Sin despertar mayores cuestionamientos, la norma que permitía la reanudación de faenas se traspasó de legislación en legislación durante todo el siglo XX, y hasta nuestros días. Por ejemplo, el Código del Trabajo del 1987 (siguiendo al Decreto Ley Nº 2.200, de 1978) estableció, también, la reanudación de faenas, en el antiguo artículo 353 de dicho cuerpo legal (con la salvedad que, se eliminó el plazo máximo de duración de la medida de reanudación que era de 90 días. Transcurrido dicho término sin que se alcanzara acuerdo entre las partes, quedaba sin efecto el decreto de reanudación, debiendo volverse al estado de huelga o lock-out en las condiciones que existían al momento de decretarse la medida. Asimismo, se entendían reanudados los plazos en el punto en que se hallaban y corrían hasta su expiración ${ }^{9}$ ). La misma lógica siguió la Ley $\mathrm{N}^{\circ} 19.069$, y el Código del Trabajo de 1994 y $2002^{10}$.

La reforma laboral recientemente aprobada, mantuvo la lógica y la estructura de esta figura limitativa del derecho de huelga y del cierre temporal de empresa. Aun cuando no acogió las solicitudes tendientes a eliminar este tipo de normas (o bien a que sólo se mantuviera en servicios esenciales que afecten a grupos significativos de la población) ${ }^{11}$, en la práctica realizó un cambio sustancial desde el punto de vista del sujeto autorizado para decretar la reanudación. En efecto, si en la legislación laboral anterior a la reforma era el Presidente de la República el encargado de evaluar la paralización o cierre, y exigir a partir de allí la reanudación, ahora esa atribución sólo le

cada uno de ellos lleva envuelta las características del servicio público, como son la satisfacción de la necesidad pública, la regularidad y la continuidad.

${ }^{8}$ Dictamen de la Inspección General del Trabajo No 1.668 , de 05 de marzo de 1938.

9 Cfr., Thayer Arteaga, William, Y Novon Fuenzalida, Patricio, Manual de Derecho del Trabajo (2a edición, Santiago, Editorial Jurídica de Chile, 1987), T.I p. 482.

${ }^{10}$ DFL N $^{\circ}$ 1, de 2002, del Ministerio del Trabajo y Previsión Social, que Fija el texto refundido, coordinado y sistematizado del Código del Trabajo.

${ }^{11}$ Véase, CÁmARA DE Diputados, Informe de la Comisión de Trabajo y Seguridad Social, recaido en el proyecto de ley que moderniza el sistema de relaciones laborales, introduciendo modificaciones al Código del Trabajo. Boletín No 9835-13-1, en www. camara.cl. 
corresponde a la autoridad judicial, previa solicitud de parte. Por tanto, en el diseño del nuevo artículo 363 cualquiera de los intervinientes en el conflicto (v. gr., empresa, sindicatos o autoridad administrativa) podrá solicitar -bajo las formalidades del procedimiento monitorio- la reanudación de faenas ante el respectivo Tribunal de Letras del Trabajo. Y en caso de acceder a la misma, se entenderá que la reanudación se efectúa en las mismas condiciones vigentes en el momento de presentar el proyecto de contrato colectivo.

Como se puede observar, la figura que analizamos es bastante peculiar y muy propia del Derecho colectivo chileno. Su regulación deja en evidencia una renuncia del Estado a un principio de no intervención en los conflictos colectivos, privilegiando el término de la paralización en razón de bienes jurídicos relevantes. Salvo algunos casos aislados, la tendencia legislativa comparada también se orienta por establecer mecanismos que impidan la huelga en actividades consideradas esenciales para la economía de un país o que permitan el funcionamiento de servicios mínimos; pero no existen de manera generalizada normas como las que consagra el actual artículo $363^{12}$.

${ }^{12}$ Una excepción a lo que se viene diciendo puede encontrarse en el artículo 464 del Código Sustantivo del Trabajo de Colombia. De acuerdo con dicho precepto, las empresas de servicios públicos que no dependan directa ni indirectamente del Estado no podrán suspender ni paralizar labores sino mediante permiso del Gobierno o dándole aviso a éste con a lo menos seis meses de anticipación, "a fin de que puedan tomarse oportunamente las providencias que aseguren la continuidad del servicio". Consecuente con lo anterior, el artículo 465 de dicho cuerpo legal establece una norma muy similar a la reanudación de faenas consagrada en el derecho chileno, al estipular que en cualquier caso en que se presentare, de hecho, la suspensión de las labores en alguna de las empresas de servicios públicos que no dependan directa ni indirectamente del Estado, "el Gobierno queda autorizado para asumir su dirección y tomar todas las providencias necesarias para restablecer los servicios suspendidos y garantizar su mantenimiento". Por su parte, el artículo 483 (contenido, al igual que las otras normas citadas, en el capítulo correspondiente al cierre de empresas), establece que en caso de producirse la reanudación de faenas en entidades que no sean de servicio público, el empleador deberá admitir de preferencia el personal licenciado, en condiciones no inferiores a las de que disfrutaba en el momento de la clausura. Si los trabajadores afectados no se presentan a sus labores dentro de tercero día contado desde la fecha del aviso correspondiente, se entenderá que pierden su derecho preferente. Por otra parte, en el mismo entorno latinoamericano, encontramos una norma de comparación en el Código del Trabajo de Costa Rica, el cual señala en el inciso segundo de su artículo 388, que "en caso de huelga o paro ilegal, los Tribunales del Trabajo ordenarán a las autoridades de policía que garanticen por todos los medios a su alcance la continuación de los trabajos; y si se tratare de servicios públicos en manos de empresarios particulares, el Poder Ejecutivo podrá, con ese fin, asumir su control temporal'. En lo que respecta a los ordenamientos europeos, algunas referencias al tema es posible encontrar en países como Francia y Gran Bretaña. En esta línea, el derecho francés consagró en textos legales de los años 1959 y 1962 la llamada figura de la requisa, en cuya virtud se admitió que un decreto adoptado por el Consejo 


\section{LOS REQUISITOS DE PROCEDENCIA}

El artículo 363 del Código del Trabajo se encarga de establecer perentoriamente cada uno de los requisitos, a objeto de que la autoridad judicial pueda ordenar la medida de reanudación de faenas. Dichos requisitos ponen el acento, por una parte, en el carácter facultativo de la medida, así como en el necesario requerimiento previo de alguno de los intervinientes en el proceso de negociación.

1. La paralización debe tener su origen en una huelga o cierre temporal, realizado dentro de un contexto de negociación colectiva. Durante la vigencia de la legislación laboral anterior a la reforma, la mayor parte de la doctrina y jurisprudencia fueron uniformes en señalar que el conflicto que origina la paralización debe tener su fundamento en acciones de huelga legal o lock-out (cierre temporal). Paralizaciones de otra naturaleza u origen, según esa posición mayoritaria, se verían regidas y afectadas por la disposición contenida en el artículo 38 de la Ley No 12.927 , sobre Seguridad del Estado ${ }^{13}$. El criterio recién expuesto parece confirmarse en la nueva redacción del artículo 363, precepto que se encuentra ubicado en el

de Ministros pueda limitar el ejercicio de este derecho cuando exista un grave riesgo o para asegurar la satisfacción de las necesidades esenciales del país o de la población (cfr., Jeammaud, Antoine, Huelga y Servicios Esenciales en el Derecho Francés, en Revista de Treball 12 [1990], p. 25). Por otra parte, en Gran Bretaña, la Ley sobre Poderes de Emergencia de 1920 y 1964 facultó al Gobierno para declarar un denominado "estado de emergencia" que asegura el cumplimiento de servicios esenciales para la comunidad en el evento que la huelga suponga una amenaza para el abastecimiento y distribución de alimentos, agua, combustible, luz y medios de transporte. El ejercicio de esta atribución no podía durar más de un mes, renovable, y sus disposiciones tenían un efecto máximo de siete días para el caso que hayan sido tomadas sin autorización parlamentaria (SIMPSON, Bob, Los conflictos colectivos en el sector público en Gran Bretaña: el marco de relaciones legales e industriales, en Gaceta Sindical 98 [1991], p. 38). Adicionalmente, en el período 1979/1980, la Cámara de los Lores reservó para los tribunales un margen residual de actuación discrecional para conceder un requerimiento laboral, incluso cuando los organizadores de acciones sindicales pareciesen estar actuando dentro del marco de las inmunidades estatutarias, sobre todo si la acción supusiere un serio e inminente peligro para la salud o la seguridad. No obstante, a pesar de la amplitud de estas figuras, la mayor parte de ellas no fueron utilizados.

13 A esa misma conclusión llegó la Contraloría General de la República, en dictámenes de los años 1951, 1952 y 1953, al sostener que "la existencia de huelga legal es requisito necesario para que se ordene la reanudación de faenas (...)”. Cfr., ONETO Sessarego, Antonio, Tratado General sobre Reanudación de Faenas (Santiago, Ediciones Revista Técnica del Trabajo y Previsión Social, 1971), p. 51. 
capítulo VII del nuevo Libro IV sobre $\mathrm{l}$ i $\mathrm{m}$ i t a c i o n e s a l e je r c i c i o d el de recho a h u elga. La huelga a la cual se refiere este capítulo es precisamente la de carácter legal, razón por la cual la decisión de reanudar faenas no podría verificarse en procesos de paralización fuera del marco procedimental de la negociación colectiva.

Aceptando que la medida de reanudación se halla inmersa en un procedimiento general de negociación colectiva, resulta necesario que la empresa se encuentre en un estado efectivo de paralización de actividades por parte de los trabajadores, ya sea por propia decisión de éstos (como sería el caso de la huelga) o por la voluntad del empleador que ha ejercido la medida de cierre temporal. En consecuencia, es preciso que la paralización provenga de un conflicto colectivo en el cual la empresa o el servicio se encuentre afecto. Como señala un autor, comentando la similar norma del Código de 1931, fuera de este caso, el artículo es inaplicable, porque su objeto no es autorizar a la autoridad para que pueda adoptar esta medida en presencia de cualquier paralización de faenas, sino única y exclusivamente cuando ésta provenga de la causa apuntada ${ }^{14}$. Por eso, toda otra paralización, fuera de los cauces propios de una negociación colectiva reglamentada en el Libro IV del Código, derivará necesariamente en actos que no ameritan siquiera una solicitud de esta naturaleza.

Asimismo, una paralización o término definitivo de la empresa por parte del propio empleador (fuera de la hipótesis del cierre temporal), haría imposible la aplicación de este artículo, ya que ello responde al ejercicio propio de la libertad de empresa que tiene toda persona para desarrollar las actividades económicas lícitas que estime conveniente, sin más obligación que el cumplimiento de las normas legales, entre las cuales figuran, por cierto, los derechos laborales de los trabajadores. Distinto sería el caso si la acción ejercida es el cierre temporal, pues éste, a su vez, debe encuadrarse perentoriamente dentro del procedimiento de negociación colectiva.

2. Las circunstancias de la paralización deben ser de tal magnitud, que pongan en peligro bienes jurídicos de mayor jerarquía. El propio artículo 363 del Código del Trabajo, se encarga de reseñar las circunstancias que eventualmente podrían provocar un perjuicio mayor y que justificarían limitar el derecho de huelga o de cierre temporal de la empresa. Dichas circunstancias van a estar configuradas porl a s c a r a c terístic a s, la oportunidad o la duración que tenga la huelga

${ }^{14}$ Véase, AlESSANDRI RodríguEZ, Arturo, Ilegalidad del Decreto sobre Expropiación de Salitreras, en RDJ., T. XXXVII (1940), p. 225. 
o e l lo c k-o u t, lo que hará pertinente la reanudación de faenas. Por tanto, aquí se está otorgando una facultad amplia que califica, a fin de cuentas, la propia autoridad judicial. Es el respectivo Tribunal de Letras del Trabajo el que determina cual es el alcance de la paralización, al evaluar sus características, su oportunidad o su duración. Dicho de otra manera, sólo al juez le corresponde evaluar y decidir si las consecuencias derivadas de la paralización son de tal magnitud que terminan afectando en forma significativa a la población. Con todo, y si bien el vocablo p o d r á que se utiliza en el inciso primero deja al descubierto una atribución facultativa del tribunal, la resolución respectiva no puede ser meramente discrecional requiriéndose de una mínima motivación y fundamento que acredite una entidad suficiente de las características, oportunidad o duración de la huelga o cierre temporal, así como una evaluación de los antecedentes de hecho y de derecho que ha tenido el juez al momento de resolver la petición. Esa motivación y fundamento forma parte del derecho a defensa de los intervinientes en el proceso ${ }^{15}$.

Las tres circunstancias anotadas (c a r a c t e rís t i c a s, o port u $\mathrm{n}$ id a d y d u ración $\mathrm{n}$ ) deben ser entendidas de manera general, en el sentido que intentan cubrir cualquier perturbación que, evaluada por el juez, permita inferir un daño a bienes jurídicos de mayor relevancia social y que al tribunal le parece necesario proteger como garante del bien común. En este sentido, hay que destacar que en la reanudación de faenas más que el número de personas efectivamente paralizadas, lo importante son los efectos de dicha paralización, el grado en que se vea menguada la producción o los perjuicios que la marcha de la empresa, así afectada, ocasione a la población, al medio ambiente, a la economía del país o a la seguridad naciona ${ }^{16}$. Sin embargo, hay que tener presente que aquí no se trata de elementos que deban concurrir conjuntamente o con la misma intensidad. Bastará que uno de ellos esté presente en la paralización, para que la autoridad judicial estime necesario ejercer esta prerrogativa. Podrá suceder, por ejemplo, que las características y la oportunidad sean perfectamente legítimas y racionales, pero que en atención a su duración, al tiempo transcurrido, se haga indispensable reanudar las labores.

De este modo, mediante esta fórmula legal se privilegia la continuidad de servicios que resultan indispensables para la comunidad, y cuya paralización supone afectar bienes de tanta importancia para la sociedad, que es preferi-

${ }^{15}$ Cfr., artículo 459 № 5 del Código del Trabajo. En el plano doctrinal, véase además Cabezas Pereiro, Jaime, La imposición de servicios mínimos, en Baylos GraU, Antonio (coordinador), Estudios sobre la huelga ( $1^{\text {a }}$ edición Albacete, Bomarzo, 2005), p. 173.

${ }^{16}$ Cfr., Oneto Sessarego, cit. (n. 13), p. 53. 
ble prohibir la huelga a objeto de asegurar el funcionamiento del servicio ${ }^{17}$. Ello, sin embargo, no impide que estas referencias tengan una alta dosis de indeterminación, fundándose sobre juicios valóricos que le otorgan a estos conceptos una evidente elasticidad.

3. Que las circunstancias señaladas causen grave daño a la salud, al medio ambiente, al abastecimiento de bienes o servicios de la población, a la economía del país o a la seguridad $\mathrm{n}$ a c i o n a l. En estos elementos radica el núcleo central de la facultad otorgada a la autoridad judicial. Existen bienes jurídicos de tal naturaleza, que el legislador estima necesario otorgar al juez una herramienta que le permita limitar determinadas paralizaciones cuyos eventuales excesos atentan contra estos bienes específicos. Por tanto, como se ha dicho, enfrentados a la colisión entre el legítimo derecho de huelga o cierre temporal, y la seguridad general, contenida en las figuras reseñadas, el ordenamiento jurídico opta por aquél bien que considera de mayor relevancia.

Como se puede observar, en la redacción legal hay una clara similitud con la norma consagrada en el inciso final del artículo $19 \mathrm{~N}^{\circ} 16$ de la Constitución (en lo que respecta a los supuestos de prohibición de huelga). Y, por cierto, expresiones tales como el grave daño, la salud, el abastecimiento de la población, la economía o la seguridad nacional, reconducen esta normativa a bienes jurídicos indeterminados que desde antiguo han venido consagrándose en preceptos de esta naturaleza.

Cuando la ley habla de g r a v e $\mathrm{d}$ a ñ o, intenta vincular este concepto con la figura del perjuicio, cierto y seguro ${ }^{18}$; es decir, un resultado dañoso de especial significación, en proporciones tales que van más allá de un mero trastorno económico, y que en consecuencia justifica la medida de reanudación. Asimismo, cuando se hace referencia a la s a l u d, a l a b a s te ci miento, al medio a mbiente o a la economía, lo

${ }^{17}$ Como señala parte de la dogmática laboral, con el establecimiento de límites al derecho de huelga se quiere evitar un perjuicio más grave que aquél que los huelguistas experimentarían si su reivindicación o pretensión no tuviere éxito. "La limitación de la buelga resulta, asi pues, de una ponderación de los bienes en conflicto". Véase MARTIN VALverde, Antonio, RodrígueZ-Sañudo Gutiérrez, Fermín, y García Murcia, Joaquín, Derecho del Trabajo (24a edición, Madrid, Tecnos, 2015), pp. 418 ss. Véase, también, PALOMEQUe LOPEZ, Manuel Carlos, El derecho constitucional de huelga y su regulación en España, en Revista de la Facultad de Derecho de la Universidad Complutense de Madrid 17 (1993), pp. 51 y ss.

${ }^{18}$ Cfr., Davila IzQuierdo, Oscar, Ilegalidad del decreto sobre expropiación de salitreras, en RDJ., T. XXXVII (1940), p. 251. Véase también Oneto SeSSAREgO, cit. (n. 13), p. 53. 
que se busca recalcar es un criterio objetivo que se independiza del régimen jurídico aplicable a las personas que pretenden ejercer el derecho de huel$\mathrm{ga}^{19}$. A mayor abundamiento, lo que intenta la norma es recalcar el criterio de que un $\mathrm{grave} d$ a ñ o sobre cada una de las figuras mencionadas implica un atentado a derechos esenciales de las personas, en su acceso a bienes y servicios considerados indispensables para la comunidad, o para el Estado. Como se ha dicho a partir del análisis de la norma constitucional, pero aplicable al presente caso, las referencias que efectúa el legislador no se vinculan con actividades secundarias, o que se trasunten en meros intereses particulares de empresarios o grupos de trabajadores; se trata, en definitiva, de actividades que afectan a la Nación toda o a una parte significativa de ella, la cual debe acceder a bienes y servicios estimados indispensables para su subsistencia y desarrollo, y que se vería afectada con una paralización de actividades de esta índole ${ }^{20}$.

Variados son los ejemplos que podrían citarse en relación con las hipótesis de esta norma. En efecto, se entenderían afectados estos bienes jurídicos con el cierre de una empresa de agua potable, o con la paralización generalizada de los servicios de hospitales, lo que ciertamente afectaría la salud de la población. En cuanto al peligro económico-social, es evidente que la ley se ha referido a un efecto de carácter amplio, "a una paralización que trastornaría fundamentalmente las condiciones de la vida de la población en general de una extensa zona (...)" ${ }^{21}$

${ }^{19}$ Cfr., Baylos Grau, Antonio, Derecho de huelga y servicios esenciales (2a edición, Madrid, Tecnos, 1988), p. 93.

${ }^{20}$ Véase Irureta Uriarte, Pedro, Constitución y orden público laboral. Un análisis del artículo $19 N^{\circ} 16$ de la Constitución chilena, en Colección de Investigaciones Jurídicas 9 (Santiago, Facultad de Derecho de la Universidad Alberto Hurtado, 2006), pp. 201 y ss.

${ }^{21}$ Véase, DÁvila IzQuierdo, cit. (n. 18), p. 251. Un criterio similar han sostenido otros autores (ONETO SESSAREgo, cit. [n. 13], p. 53), al señalar que "debe tratarse de un peligro bastante generalizado que afecte a todo o parte de la población nacional. Además, el peligro no debe ser lejano 'o a la larga', debe ser inmediato, contiguo, sin tardanza. El peligro debe ser cierto y seguro. No eventual (...)". En cuanto a la jurisprudencia administrativa, habrá que reconocer que durante la vigencia del Código de 1931 ésta tenía un criterio algo contradictorio. En algunos casos, la Contraloría General de la República concluyó que "todo decreto que ordene la reanudación de faenas debia contener las consideraciones acerca de que a juicio del Supremo Gobierno, la paralización de faenas de que se trata pone en peligro inmediato la salud o la vida socio-económica de la población", agregando que, por ejemplo, la paralización en una fábrica de calzado, cerveza o de artículos eléctricos, no podía ser considerada como atentatoria hacia los bienes jurídicos que se intentaban proteger con la reanudación de faenas (Vergara Baeza, Juan de Dios, y Cavalli Benzi, Aldo, Derecho de Huelga, Reanudación de Faenas, Intervención [Santiago, Ediciones López Viancos, 1972], p. 61). No obstante, en dictámenes posteriores la propia 
En síntesis, el análisis de los elementos a que se refiere el artículo 363 requiere un estudio caso a caso de las circunstancias concurrentes. Y dentro de esas circunstancias habrá que tomar en cuenta la duración o extensión de la huelga, su eventual efecto multiplicador, las fechas de su convocatoria, los bienes afectados, la existencia de alternativas para satisfacer estos bienes jurídicos, o el grado de perturbación de los usuarios, por mencionar algunas alternativas ${ }^{22}$.

4. La facultad concedida se refiere sólo a la reanudación de faenas, la que debe ser ordenada mediante resolución judicial. Lafacultadotorgada por el legislador se refiere sólo a las medidas conducentes a la reanudación de las faenas. Aquí no cabe, por ejemplo, la incautación o intervención de la empresa; sólo se precisa reanudar las actividades, cosa que podrá conseguirse de diversos modos, sin que se haga necesario recurrir a figuras jurídicas que afecten el derecho que tiene el titular de la actividad productiva. Por tanto, la resolución judicial respectiva deberá señalar las medidas que se consideren necesarias para lograr el objetivo señalado en la ley.

De esta manera, la atribución judicial sólo puede ejercitarse para hacer cesar la situación legal de huelga o cierre temporal, indicando los medios necesarios para dicho fin. Ello no implica, por cierto, una facultad absoluta y arbitraria, sino que sólo la aplicación de aquél procedimiento que facilite el retorno a las labores, y el amparo de la libertad de trabajo. Será el empleador, por su parte, el encargado de implementar la reanudación práctica de las faenas ${ }^{23}$, la cual incluye la eventual contratación del personal necesario

jurisprudencia de la Contraloría se inclinaba por la tesis que la reanudación de faenas establecida en el antiguo artículo 626 (547) del Código de 1931 otorgaba una facultad amplia para determinar aquellas actividades de relevancia en la vida económica y social del país respecto de las cuales se consideraba necesario adoptar la señalada medida: "Se trata de una apreciación de hecho que, dentro de nuestro régimen jurídico, debe calificar autónomamente el Poder Ejecutivo, puesto que sólo al Presidente de la República, en su carácter de supremo administrador del Estado, compete la calificación de la conveniencia y oportunidad de los actos de la administración" (Ibídem, p. 61). En otro dictamen de la jurisprudencia administrativa, se expuso la tesis que la Contraloría debía hacer fe en las afirmaciones del Gobierno en cuanto a los hechos que sirven de base a la declaración de reanudación de faenas, siempre que ellos materialmente no puedan acreditarse. Sobre esto último, véase CAVAlLi BENZI, Aldo, La Reanudación de Faenas (Santiago, Memoria de Prueba, Facultad de Derecho, Pontificia Universidad Católica de Chile, 1968), p. 56.

${ }^{22}$ Cfr. Cabezas Pereiro, cit. (n. 15), pp. 182 y 183.

${ }^{23}$ Cfr., en relación con otras figuras limitativas del derecho de huelga, pero aplicable al presente caso, Pérez ReY, Joaquín, El incumplimiento de los servicios minimos y su revisión judicial en las huelgas que afectan a los servicios esenciales de la comunidad", 
en caso de no acatarse total o parcialmente la orden de reanudación ${ }^{24}$. Lo anterior no enerva la facultad judicial de evaluar la manera en que se ha implementado la sentencia que ordenó la reanudación. Cabe hacer presente, en todo caso, que una vez ejecutoriada la sentencia que ordena la reanudación difícilmente ésta podría ser reevaluada. Lo que ocurre es que -ordenada la reanudación- la negociación colectiva ha seguido un cauce distinto, y sólo puede ser resuelta mediante el arbitraje obligatorio.

En cuanto a las características de la resolución judicial, resulta evidente que el juez deberá dictar sentencia al término de la audiencia respectiva, la que deberá contener las menciones señaladas en los números 1, 2, 5, 6 y 7 del artículo 459 del Código del Trabajo. Además, la sentencia en cuestión deberá indicar los fundamentos de la medida y la referencia específica de la paralización cuya reanudación se decreta. De esta manera, el dictamen judicial será fundado y expresará las razones de mérito o conveniencia que justifican la aplicación de la norma legal en comento.

Probablemente, uno de los cambios formales más evidente que trasunta el cambio del sujeto habilitado para decretar la reanudación (desde el Presidente de la República al Tribunal de Letras del trabajo) es la demora que supone la tramitación de un procedimiento monitorio. No hay que olvidar que durante la vigencia del Código de 1931, la jurisprudencia administrativa estimaba que la reanudación podía ser inmediatamente decretada por el Poder ejecutivo (sin perjuicio de la revisión posterior de la legalidad del decreto supremo) ${ }^{25}$. Sin embargo, en la redacción actual el solicitante debe esperar que la resolución respectiva se encuentre ejecutoriada. Por ello, extraña que el artículo 363 no haga mención alguna a la posibilidad de aplicar medidas cautelares durante la tramitación de la solicitud. No obstante, a nuestro juicio, nada impide que el juez de la causa haga uso de estas medidas de conformidad con las reglas generales. Por lo demás, el artículo 404 del nuevo texto legal faculta al tribunal para que, mediante resolución fundada, disponga la suspensión de la negociación colectiva en curso.

en Baylos Grau, Antonio (coordinador), Estudios sobre la huelga ( $1^{\text {a }}$ edición Albacete, Bomarzo, 2005), p. 221.

${ }^{24}$ Cfr., Alvear Urrutia, Eduardo, El Arbitraje ante la Legislación del Trabajo, en RDJ., T. XXXIX (1942), p. 64.

${ }^{25}$ Véase Dictamen N N $^{\circ} 9.659$, de 05 de mayo de 1971, de la Contraloría General de la República, el cual concluyó que: "nada se opone legalmente a que un decreto de reanudación de faenas sea cumplido antes de su envio a control, para su toma de razón, ya que estos deben ser ejecutados tan pronto como sean dictados, como la misma norma lo establece, sin perjuicio de tramitarse posteriormente". 


\section{LOS EFECTOS DE LA REANUDACIÓN DE FAENAS}

Las consecuencias de la sentencia que ordena reanudar las faenas son bastantes claras, al tenor de lo señalado en el artículo 363, y básicamente reflejan un límite efectivo al ejercicio del derecho de huelga.

1. Los trabajadores afectados por la huelga o por el cierre temporal, deben volver a sus labores y la empresa reanudar su actividad. La primera consecuencia directa de la resolución que acepta reanudar las faenas será la obligación de los trabajadores de reincorporarse a sus labores en la empresa paralizada, dejándose sin efecto el movimiento huelguístico o la decisión del empleador de decretar el cierre temporal. De conformidad con lo que establece el inciso tercero del artículo 363, el empleador y los trabajadores reanudan las faenas en las mismas condiciones vigentes al momento de presentar el proyecto de contrato colectivo. Por lo tanto, los trabajadores no pueden gozar de menos derechos que los que tenían al momento de iniciarse el proceso de negociación. Naturalmente, si se ha producido un mejoramiento legal de los derechos labores, como podría ser un reajuste de remuneraciones $\mathrm{u}$ otro beneficio análogo, dichas normas se entenderán incluidas en las respectivas condiciones que afectan a las partes.

Como consecuencia de lo anterior, tanto los trabajadores como los empleadores se encuentran obligados a concurrir a sus funciones y reiniciar las actividades de la empresa, siendo plenamente eficaces los efectos del contrato de trabajo los cuales no podrán entenderse suspendidos. En el evento que los trabajadores se negaran a reincorporarse, se estaría en presencia de una actitud ilegal a la cual se le podrían aplicar las normas generales sobre incumplimiento contractual. No obstante, habrá que reconocer que en estos casos el poder disciplinario del empleador no puede asimilarse a un simple instrumento de garantía de las exigencias contractuales asumidas por el trabajador. A fin de cuentas, el artículo 363 no busca satisfacer el interés del empleador sino que proteger los bienes jurídicos que indica la norma antes señalada ${ }^{26}$.

${ }^{26}$ Cfr., a nivel doctrinario, Pérez Rey, cit. (n. 23), p. 213. Y agrega en p. 219 (en relación con otra figura limitativa del derecho de huelga, pero aplicable al presente caso): el despido del trabajador "no se basa, en puridad, en un incumplimiento contractual, elemento imprescindible junto a la gravedad y la culpabilidad para fundar la extinción unilateral del contrato de trabajo, sino en la inobservancia de obligaciones ajenas al contrato pero que se cumplen a través de él y que para dotarlas de 'apariencia' contractual se acude a la técnica interpretativa en virtud de la cual se considera que la falta de respeto a las disposiciones de la autoridad gubernativa (judicial) suponen, a su vez, la desobediencia de la orden empresarial en que ellas se funda". 
Por otra parte, si la paralización se ha producido por la aplicación del cierre temporal, y el empleador se niega a reanudar las faenas en la empresa, entonces el incumplimiento recaería sobre éste y podría aplicarse en toda su plenitud la institución del despido indirecto, sin perjuicio de las sanciones civiles o penales que procedan por la negativa a obedecer una orden emanada de la autoridad judicial ${ }^{27}$.

Como señala un autor, en el evento que las partes en un contrato de trabajo no reanuden sus labores, se colocan entonces en rebeldía con la ley y con su contrato, debiendo sufrir las sanciones respectivas para el caso de abandono de sus labores ${ }^{28}$. Este criterio es aplicable tanto a trabajadores como empleador. No obstante, hay que tener presente que, de conformidad con el artículo 309 del Código, los trabajadores involucrados en un proceso de negociación colectiva gozan de fuero laboral. Por ello, en el caso que exista un incumplimiento de las obligaciones contractuales, una vez reiniciadas las faenas, la posibilidad de terminar el contrato de un trabajador que se niega a reincorporarse necesariamente tendrá que ser efectuada por la vía judicial en un procedimiento de desafuero. Asimismo, al retrotraerse la reanudación a la época de presentación del proyecto de contrato colectivo, nada impide que el empleador pueda contratar personal adicional ${ }^{29}$.

2. La resolución que ordena reanudar faenas, obliga a someter el proceso de negociación a la intervención de un árbitro laboral. En efecto, según lo dispone el inciso $4^{\circ}$ del artículo 363 , la sentencia judicial que ordena reanudar las faenas -y que se encuentre debidamente ejecutoriada- "deberá notificarse a la Dirección del Trabajo para los efectos de lo dispuesto en el artículo 387”. Este último precepto se refiere precisamente a la designación del tribunal arbitral ${ }^{30}$.

${ }^{27}$ En estos casos, serían aplicables, por ejemplo, las sanciones establecidas en los artículos 11 y 12 de la Ley No 12.927, sobre Seguridad del Estado. En efecto, el primero de los artículos mencionados sanciona toda interrupción o suspensión colectiva, paro o huelga de los servicios públicos o de utilidad pública, así como de otras industrias consideradas vitales. Por su parte, el artículo 12 de la referida ley sanciona con las penas de presidio o relegación menores en su grado mínimo a medio, y multas, a "los empresarios o patrones que declaren el lock-out o que estuvieren comprometidos en los delitos contemplados en el artículo precedente".

${ }^{28}$ Cfr., Alvear Urrutia, cit. (n. 24), p. 64.

${ }^{29}$ Lo anterior se entiende, siempre y cuando dicha conducta no implique un supuesto de práctica desleal de conformidad con lo establecido en el nuevo texto de los artículos 403 y 404 del Código del Trabajo.

30 Según el inciso segundo del artículo 387, "suscrito el compromiso entre las partes, llegada la fecha de término de vigencia del instrumento colectivo o a partir del día 
Este precepto sigue el mismo criterio que mantenía el Código de 2002, rechazando la posibilidad de una mediación obligatoria para conseguir una solución al conflicto cuya reanudación se ordenaba. La ley actual, por el contrario, consideró preferible someterlo a la intervención de un árbitro en atención a las facultades y procedimientos que rigen la acción de estos jueces. Desde esta perspectiva, y tal como se establece en el inciso segundo del artículo 386 del Código, en estos casos el arbitraje laboral resulta obligatorio, en atención a que la determinación judicial requiere solucionar el conflicto existente, para lo cual utiliza este procedimiento que asegura un buen término de la negociación colectiva.

Con todo, hay que tener presente que la medida de reanudación de faenas, por sí sola, no termina con el conflicto colectivo. Por ello se justifica la designación de un árbitro, pues conjuntamente con la reiniciación de las actividades, es preciso asegurar que el conflicto colectivo tendrá solución dentro de un contexto temporal prudente. Por ello, el árbitro designado tendrá un carácter esencialmente transitorio, toda vez que cuenta con un plazo máximo para fallar el conflicto de 30 días hábiles contados desde el momento mismo de su constitución, plazo que podrá prorrogarse fundadamente por otros diez días hábiles (art. 391). Por tanto, la transitoriedad del procedimiento está supeditada necesariamente a un plazo determinado, en el cual el tribunal estará obligado a fallar en favor de una de las dos proposiciones planteadas por las partes que intervienen en el conflicto, y que se encuentren vigentes en el momento de someterse el caso a arbitraje, debiendo el juez árbitro aceptar alguna de las proposiciones en su integridad (art. 390, inciso primero). La transitoriedad se ve reflejada, también, en el hecho que el árbitro sólo está facultado para solucionar el conflicto específico que se le somete a su jurisdicción, y no otros que eventualmente pudiesen surgir en la empresa.

\section{La Reanudación de faenas en la Ley de SEGURidad DEL ESTADO}

La norma del artículo 363 del Código del Trabajo no es la única que reglamenta figuras de reanudación obligatoria. En efecto, en el ámbito penal también se da la hipótesis de la reanudación de faenas, cuando la paralización cause grave daño en industrias vitales para la economía nacional (aun cuando habrá que reconocer que su aplicación práctica ha sido casi inexistente en las últimas décadas). Según se establece en el artículo 38 de la Ley No

siguiente de la notificación de la resolución que ordena la reanudación de faenas, la Dirección Regional del Trabajo (...) deberá citar a las partes a una audiencia dentro de quinto día para la designación del tribunal arbitral, la que se llevará a cabo con cualquiera de las partes que asista o en su ausencia de ambas". 
12.927, sobre Seguridad del Estado, "en caso de paralización ilegal que cause grave daño en industrias vitales para la economía nacional o de empresas de transportes, predios o establecimientos productores o elaboradores de artículos o mercaderías esenciales para la defensa nacional o para el abastecimiento de la población o que atiendan servicios públicos o de utilidad pública, el Presidente de la República podrá decretar la reanudación de faenas con intervención de las autoridades civiles o militares".

Esta norma es de carácter complementaria a la establecida en el artículo 363 del Código del Trabajo, pero con la particularidad que se aplica exclusivamente a aquellas paralizaciones ilegales. En este sentido, la facultad del Presidente de la República se inserta en el campo punitivo, a fin de remediar una actitud contraria al ordenamiento jurídico y para restablecer rápidamente los servicios que se consideran esenciales para la comunidad. Por tanto, ésta es una figura diversa de la sancionada en la legislación laboral, con una aplicación bastante más amplia.

Entre los elementos distintivos de esta norma, es dable destacar los siguientes requisitos que se exigen para decretar la reanudación de faenas:

1. Debe existir una paralización ilegal de a c t ividades. La ley pone el acento en el hecho que exista una paralización efectiva. Por cierto, ésta tendrá necesariamente un carácter de ilegalidad, ya que si la paralización llegare a encuadrarse dentro del marco jurídico nos enfrentaríamos a una huelga o lock-out regido por la normativa del Código del Trabajo; y en vez de aplicar la resolución judicial de reanudación fundado en la norma penal, sería de toda concordancia aplicar el comentado artículo 363.

La expresión i l e g a 1 , que utiliza el artículo 38 de la Ley $\mathrm{N}^{\circ} 12.927$, parece enfocarse en la idea de conflictos que salgan de la regulación formal del Código del Trabajo. A fin de cuentas, y más allá del alcance que la jurisprudencia le haya otorgado al derecho fundamental de huelga, lo cierto es que la facultad presidencial sólo tendría sentido en la medida que la paralización se encuentra fuera de los supuestos de huelga que regula el Libro IV del Código. De otra forma, la norma carecería de sentido y estaría vaciada de aplicación práctica.

En consecuencia, basta una simple paralización de la empresa para que se entienda procedente el decreto de reanudación de faenas por aplicación de la normativa propia de la Ley de Seguridad del Estado. Como señalan Vergara y Cavalli, lo sustantivo para que proceda esta medida es que exista una paralización de actividades, sin que sea suficiente que una parte de los 
trabajadores se encuentre en huelga y otro grupo siga prestando servicios normalmente ${ }^{31}$.

La jurisprudencia administrativa, interpretando esta normativa, ha sostenido que para poder aplicar la norma penal, es preciso que la paralización sea el fruto de un conflicto de trabajo y que el mismo sea planteado por el propio personal. Dentro de esta normativa, no parece lógico ese criterio; perfectamente se puede producir una paralización ilegal, con diversas orientaciones, absolutamente ajenas al campo laboral, incluso con participación de terceros, e igual debiera ser procedente el decreto de reanudación de faenas. En este sentido, cabe destacar que el artículo 38 de la Ley No 12.927 pone el énfasis en el hecho que exista una paralización ilegal, independiente de las motivaciones que hayan tenido los trabajadores para incurrir en dicha práctica.

2. Que la paralización cause grave daño en industrias vitales para la economía. Esta expresión tiene un carácter genérico, e intenta contemplar en ella cualquiera paralización ilegal que involucre efectos negativos para la población. Por tanto, la referencia al grave daño significa que la inactividad acarrea un perjuicio de tal naturaleza, que se ve afectada una parte significativa de la comunidad en el acceso a determinados bienes o servicios esenciales. Al respecto, la jurisprudencia ha señalado que la expresión in d us t rias vitale $s$ dice relación con "aquellas que influyen fundamentalmente sobre la economía del pais, por ser de suma importancia y trascendencia" 32 .

De igual modo, la propia norma del artículo 38 de la Ley de Seguridad del Estado se encarga de mencionar, a título sólo referencial, las industrias consideradas vitales para la economía del país. Entre ellas destacan las empresas de transportes, predios o establecimientos productores o elaboradores de artículos o mercaderías esenciales para la defensa nacional o para el abastecimiento de la población, y aquellas entidades que atiendan servicios públicos o de utilidad pública. En esta enumeración legal se observa que el objetivo central de la norma consiste en asegurar la tranquilidad social y el bienestar económico del país, así como el orden público que, en caso contrario, se vería seriamente amagado. Por tanto, existe para el legislador un bien jurídico esencial que pretende proteger, cual es la estabilidad social.

Durante la discusión parlamentaria de las Leyes sobre Seguridad del Estado, se dejó constancia que cuando se hablaba de s e r v i c i o pú b li c o se estaba haciendo mención a todo servicio técnico prestado al público de una

31 Vergara y Cavalli, cit. (n. 21), p. 71.

32 Véase sentencia de la Corte de Apelaciones de La Serena de 13 de marzo de 1954, en RDJ., T. II, sección cuarta (1954), p. 123. 
manera regular y continua para la satisfacción de una necesidad pública y por una organización también pública, "siendo tales, los de alumbrado eléctrico, de gas y de agua potable, porque éstos son elementos indispensables para la vida de una ciudad; y servicios de utilidad pública, son los establecimientos creados por los particulares y autorizados por el Estado que tienden en forma permanente y continua a un fin de utilidad, reservándose la autoridad la facultad de controlar su funcionamiento. Se considera que son servicios de utilidad pública la movilización urbana y suburbana, el servicio telefónico o telegráfico, el transporte ferroviario, maritimo, lacustre y fluvial, el transporte aéreo y caminero, el aseo en calles y plazas y otros similares" 33 .

El problema que surge a este respecto es que numerosos servicios, que atienden necesidades públicas, no se encuentran sometidos a la dependencia o supervigilancia del poder estatal. En esta perspectiva, la norma de la Ley de Seguridad del Estado no debiera entenderse sólo circunscrita a este último aspecto, ya que el bien jurídico que se pretende proteger es justamente la satisfacción de necesidades esenciales de la población, independiente de la naturaleza jurídica del ente que otorga la prestación. Esta disyuntiva cobra mayor importancia hoy en día en la medida que existe una redefinición del concepto de sector público y de sector privado, y en que la definición de $\mathrm{n}$ e c e s i d a d p ú b l i c a tiene un alcance mayor al de aquellos servicios administrados por el poder estatal ${ }^{34}$.

La constante expansión, al menos histórica, que presentaron numerosas paralizaciones de actividades industriales, abarcando incluso campos reservados al derecho administrativo, puso en jaque la subsistencia de ciertas

33 Véase, RDJ., T. LXIX, sección cuarta (1972), p. 163.

${ }^{34}$ La jurisprudencia administrativa ha señalado, por su parte, que la expresión sector público, asimilada al concepto jurídico de servicios integrantes de la Administración del Estado, comprende a todas las personas administrativas o servicios públicos, sean éstos fiscales, dependientes o no de la Administración Central, o descentralizados. " $A$ dicha conceptualización se contrapone la de 'sector privado' del Estado, es decir el constituido por servicios o entidades que no están comprendidos en la Administración del Estado por haber adoptado en su organización fórmulas de derecho privado" (Dictamen No 20.898/76, citado en Repertorio de Legislación y Jurisprudencia chilenas, Leyes administrativas sobre Municipalidades (2o edición, Santiago, Editorial Jurídica de Chile, 1994), p. 9. Una visión más panorámica de este fenómeno, puede consultarse en VERGARA BlanCO, Alejandro, El nuevo servicio público abierto a la competencia: de la publicatio al libre acceso. Coherencia de las viejas técnicas concesional y autorizacional, en Revista de Derecho Administrativo Económico 12 (2004), pp. 33 a 49; y del mismo autor, Una triada económica y jurídica: recursos naturales, bienes públicos y servicios públicos conexos para un balance de 30 años de liberalización económica en Chile (1980-2010), en FERRADA Bórquez, Juan Carlos (coordinador), Estudios de Derecho Público. El principio de separación de poderes. Actas de las XL Jornadas de Derecho Público 2010 (Santiago, Abeledo Perrot-Thomson Reuters, 2011), pp. 651-673. 
entidades que prestaban servicios fundamentales para las personas. De esta forma, según señala Cassagne, determinados conflictos sociales se agudizaron amenazando hasta la propia subsistencia de los ciudadanos ${ }^{35}$, lo que ha dado origen al establecimiento, dentro del ámbito jurídico, de los llamados servicios esenciales destinados a resolver necesidades de carácter público. Por ello, en la comprensión de qué actividades afectan a industrias vitales para la economía debemos destacar en ellas a los establecimientos que producen bienes o servicios indispensables para la subsistencia y la calidad de vida de las personas, independiente de si pertenecen al sector público o privado. De ahí la importancia de proteger a los usuarios de dichos servicios, pues el bien protegido es precisamente el acceso de la población a productos o servicios considerados vitales.

En relación al alcance que debe darse a los llamados servicios esenciales, habrá que encuadrar su conceptualización en el campo del servicio público, aun cuando se trata de figuras que operan dentro de categorías distintas. En este sentido, los servicios esenciales ciertamente incluirán a más de un servicio público tradicional, pero su campo de acción es notoriamente "más amplio y comprende también actividades de titularidad privada, donde no se ha operado la publicatio" ${ }^{36}$. No sólo eso, la determinación de un servicio como esencial no puede efectuarse en forma apriorística. Su delimitación, al menos en el campo teórico, tendrá que ser objeto de un análisis detallado a fin de determinar si reúne los requisitos pertinentes para proteger los derechos o bienes constitucionalmente garantizados, y que dicen relación con toda la población ${ }^{37}$.

Consecuente con lo anterior, la conclusión debe encaminarse en la lógica de que no todo servicio, por el hecho de ser público, reúne los caracteres de esencialidad. Y, por el contrario, perfectamente podremos encontrar determinadas empresas, corporaciones o entidades que, a pesar de no revestir carácter público, su esencialidad es notoria y la paralización provocaría claramente un grave daño a la población. Esta tesis cobra mayor raigambre en la medida que el Estado va cediendo terreno, en el plano económico, a la iniciativa privada para llevar a cabo proyectos esenciales y que afectan a un número significativo de personas. Por tanto, no todo servicio público puede ser catalogado, a priori, como servicio esencial; y no todo servicio esencial debe necesariamente ser de carácter público, pudiendo encontrarse dicho carácter perfectamente en actividades regidas por el derecho privado.

Por cierto, y tal como se señaló en los párrafos anteriores, la determinación

${ }^{35}$ Véase, Cassagne, Juan Carlos, La Huelga en los Servicios Esenciales (1 $1^{a}$ edición, Madrid, Civitas, 1993), p. 51.

${ }^{36}$ Ibídem (n. 35), p. 53.

${ }^{37}$ Ibídem (n. 35), p. 56. 
concreta sobre si una entidad está comprendida o no en la enumeración del artículo 38 de la Ley, será una cuestión evaluada en cada caso particular. No obstante, la jurisprudencia administrativa, conociendo de una situación específica, estimó que, por ejemplo, la agricultura no debía entenderse incluida en la enumeración señalada en el artículo 38 de la Ley No 12.927, de acuerdo con la interpretación gramatical del precepto o dentro del tratamiento que le concede la legislación chilena ${ }^{38}$. Igual derrotero siguió un fallo de la Corte Suprema con respecto a la actividad periodística, ya que si bien ésta presta servicios útiles para la población, no pueden ser considerados como servicios públicos o de utilidad pública ${ }^{39}$. Pero en general, se ha estimado que corresponde al Poder Ejecutivo allegar los antecedentes suficientes para demostrar que las faenas paralizadas son de aquellas mencionadas en la disposición en que se funda el respectivo decreto ${ }^{40}$.

3. La reanudación se establece mediante d e cre to s u p r e mo. Aun cuando la ley no lo dice expresamente, y a diferencia de lo que plantea el artículo 363 del Código del Trabajo, todo indica que la reanudación deberá ser ordenada por el Presidente de la República mediante decreto supremo suscrito, además, por otros ministros que, para este efecto, debieran ser los del Interior y Trabajo y Previsión Social $^{41}$. De igual modo, el mandato de la autoridad ejecutiva debe ceñirse estrictamente a lo ordenado en la Constitución y las leyes, razón por la cual el decreto debe ser fundamentado y señalar rigurosamente las razones que dan motivo a la decisión.

Como se ha dicho, la facultad otorgada por el legislador al Presidente de

${ }^{38}$ Véase, RDJ., T. LXIV, sección primera (1967), p. 116.

39 Cfr., RDJ., T. LXIX, sección cuarta (1972), p. 163. No obstante, en este fallo el voto de minoría estimó que, también, satisface la utilidad pública un diario que a través de sus columnas mantiene informada a la ciudadanía del acontecer nacional e internacional, toda vez que, a juicio de esta doctrina, "es de utilidad pública el que las labores del diario no sean paralizadas porque produciría la cesantía del numeroso personal técnico que en ellas labora con las perniciosas consecuencias de todo orden para sus respectivos núcleos familiares".

${ }^{40}$ Cfr., Jara Wolff, Octavio, La reanudación de faenas (Concepción, Memoria de Prueba. Facultad de Derecho. Universidad de Concepción, 1971), p. 23.

${ }^{41}$ En lo que se refiere a la dictación del decreto supremo, cabe tener presente que el artículo 35 de la Constitución Política establece que "los reglamentos y decretos del Presidente de la República deberán firmarse por el Ministro respectivo y no serán obedecidos sin este esencial requisito. Los decretos e instrucciones podrán expedirse con la sola firma del Ministro respectivo, por orden del Presidente de la República, en conformidad a la normas que al efecto establezca la ley". La consecuencia de estos actos implica que los Ministros serán responsables individualmente de los actos que firmaren y solidariamente de los que suscriban o acuerden con los otros Ministros (art. 36 de la Constitución). 
la República se refiere sólo a las medidas conducentes a la reanudación de las faenas. Aquí no cabe, por ejemplo, la incautación o expropiación de la empresa; sólo se precisa reanudar las actividades, cosa que podrá conseguirse de diversos modos, sin que se haga necesario recurrir a figuras jurídicas que afecten el derecho de propiedad que tiene el titular de la entidad. Por tanto, el decreto respectivo deberá señalar las medidas que se consideren necesarias para lograr el objetivo señalado en la ley, pero ello nunca podrá significar una alteración del derecho de propiedad que sigue rigiendo en toda su plenitud. De esta manera, la facultad gubernativa sólo puede ejercitarse para hacer cesar la situación de huelga o lock-out, suministrando los medios necesarios para dicho fin, expresando razones de mérito o conveniencia que justifican la aplicación de la norma legal.

Lo anterior no impide que, en la especie, se apliquen los mecanismos de control frente al decreto supremo. En efecto, por una parte la Constitución de 1980 establece la posibilidad de calificar la constitucionalidad de la decisión del Presidente en relación al decreto respectivo por parte del Tribunal Constitucional. Una segunda instancia está referida a la Contraloría General de la República a través de la toma de razón, con las limitaciones del artículo 21 B de la Ley No 10. 336 (Orgánica de la Contraloría); y, en tercer lugar, nada impide que los Tribunales de Justicia aprecien la legalidad o constitucionalidad del decreto que declara las empresas que deban reanudar sus faenas ${ }^{42}$. Dicho de otra manera, una es la decisión autónoma del Presidente de la República que evalúa las circunstancias y dicta el decreto respectivo -lo que reviste una cierta discrecionalidad toda vez que la ley le remite la apreciación de ciertos elementos a su voluntad-; y otra es la facultad que tienen los demás órganos para controlar el acto del Presidente de la República. Y esta facultad, independiente de la del Presidente, también debe estimarse autónoma. Estos órganos, por tanto, pueden controlar eventuales violaciones al ordenamiento jurídico que se verifiquen por la apreciación discrecional del Presidente, lo cual se conjuga plenamente con la facultad que se les otorga ${ }^{43}$. A mayor abundamiento, la autoridad ejecutiva goza de una gran amplitud

42 Sobre el particular, véase Hernández Emparanza, Domingo, Control de constitucionalidad de actos administrativos por el Tribunal Constitucional. Precedentes Constitucionales, en Estudios Constitucionales 4 (2006), 1, pp. 207 y ss; RAJEVIC MOSLER, Enrique, y Garcés RAMírez, María Fernanda, Control de legalidad y procedimiento de toma de razón, en AA. VV., Un mejor Estado para Chile. Propuestas de modernización y reforma. Consorcio para la reforma del Estado (Santiago, Pontificia Universidad Católica de Chile, 2009), pp. 613 y ss; y Bermúdez Soto, Jorge, Derecho Administrativo General (3a edición, Santiago, Thomson Reuter-Abeledo Perrot, 2014), pp. 523 y ss.

43 Véase, SaAvedra Fernández, Rubén, Discrecionalidad Administrativa (Santiago, LegalPublishing, 2011), p. 249. 
para calificar la conveniencia de una medida como la que consagra el artículo 38 de la Ley $\mathrm{N}^{\circ}$ 12.927; pero ello no impide que los órganos de control, dentro del ámbito de sus atribuciones, constaten si los hechos que sirven de base al acto del Presidente de la República existen, o si se compadecen con la facultad que la ley le ha entregado. Por ejemplo, podrá existir una violación legal por parte de la autoridad pública cuando se ordene la reanudación de faenas de una empresa que se encuentra paralizada no por un acto ilegal, sino por una imposibilidad económica de continuar el giro de la actividad desarrollada. O, también, cuando se ordene la reanudación de faenas en una empresa cuya paralización se efectúa dentro de la hipótesis a que se refiere el artículo 363 del Código del Trabajo (cuya calificación es resorte exclusivo del Juez de Letras del Trabajo); o, en fin, cuando se ha producido una aplicación manifiestamente irracional o desproporcionada.

4 La reanudación de faenas regulada en la Ley de Seguridad del Estado puededecretarse con la designación de un interventor, ya sea c ivil o $\mathrm{milit}$ a $\mathrm{r}$. La designación de un interventor constituye una facultad del Presidente de la República, quien podrá ordenar la reanudación, con o sin la presencia de una autoridad especialmente facultada al efecto. Lo anterior implica que, dependiendo de la gravedad de la situación, las faenas podrán reiniciarse con los mismos ejecutivos que ella tenía al momento de producirse la paralización o con la intervención de terceros ajenos al funcionamiento interno de la entidad.

En la lógica de la Ley de Seguridad del Estado, el interventor asume en calidad de funcionario público, designado por el Presidente de la República para poner término a la paralización ilegal. Su función principal, la cual no es delegable, consiste en organizar nuevamente la empresa, en restablecer el orden interno de ella y velar por el cumplimiento general del ordenamiento jurídico.

La particularidad del interventor, se traduce en la calidad que éste asume en la empresa afectada. Por razones de orden público, la autoridad designada adquiere el papel de reorganizador general de las labores paralizadas, capaz de restablecer la disciplina y normalidad interna de la empresa. No obstante, dicha calidad en modo alguno significa que el interventor pueda tener facultades de administración. Es decir, éste no cuenta con las facultades de representar a la empresa judicial o extrajudicialmente. El mismo inciso final del artículo 38 se encarga de aclarar este punto, al señalar que "el interventor tomará a su cargo las gestiones para dar solución definitiva al conflicto, pero en ningún caso tendrá facultades de administración”.

Este criterio legislativo no es nuevo, y la jurisprudencia existente sobre 
el primitivo artículo 38 ya había establecido que un decreto de intervención no podía, de ningún modo, privar a una empresa de la administración de la misma, no existiendo responsabilidad para el titular de la misma con respecto a los despidos efectuados por el interventor. Un criterio distinto, a juicio de la Corte Suprema, equivalía a otorgarle facultades al interventor para que diera una fisonomía u orientación a la empresa diversas de aquella que sus titulares habían querido otorgarle ${ }^{44}$. De esta manera, si bien el interventor asume como autoridad destinada a restablecer el orden y la disciplina interna, ello no se puede traducir, por ejemplo, en despidos de trabajadores, o en aumento o disminución de sus remuneraciones. Todas esas medidas debieran ser consultadas y acordadas previamente con el empleador.

Con todo, el problema sigue abierto si se evalúa cuál es el verdadero rol que cumple el interventor y cuáles son las atribuciones que tiene la autoridad designada. No está claro si en las gestiones para dar solución definitiva al conflicto, el interventor goza de facultades especiales para utilizar la fuerza pública con el objeto de efectuar desalojos o medidas de coacción ${ }^{45}$. Un primer camino de solución se enfoca en la perspectiva de que el propio decreto supremo que ordena la reanudación, determine cuáles son las atribuciones específicas de que goza el interventor en razón del papel que asume a nombre del Estado. Como consecuencia de lo anterior, las partes supeditan determinadas atribuciones contractuales en favor de la autoridad designada a objeto que se restablezca el orden y la disciplina interna en la empresa. Sin embargo, y aun cuando el interventor podrá reiniciar, en términos generales, las faenas, a objeto de normalizar su funcionamiento y producción, y exigir

${ }^{44}$ El caso expuesto decía relación con una empresa periodística que, en el año 1972, fue objeto de un decreto de reanudación de faenas por parte del Poder Ejecutivo, ya que se encontraba paralizada desde hacía varios meses. El problema surgió cuando el interventor fue revestido de atribuciones que le permitían contratar el personal que fuera necesario para la normalización de las labores, celebrando los contratos de trabajo pertinentes. La doctrina de la Corte, en este caso, quedó sustentada de la siguiente forma: "La libertad de información se encuentra cautelada cuidadosamente por el nuevo texto constitucional y no se puede, por medio de un decreto de intervención, privar a una empresa periodística de la administración de un diario (...) o radioemisora, porque puede constituir una forma de atentar contra el funcionamiento libre de ese medio". Véase, RDJ., T. LXIX, sección cuarta (1972), p. 159. Un criterio similar, ahora en relación con la responsabilidad de los titulares, véase también en $R D J$., T. LXVI, sección tercera (1969), p. 11.

${ }^{45}$ Ante una figura distinta, que decía relación con un interventor bancario, pero aplicable al caso que nos ocupa, la Corte de Apelaciones de Santiago indicó en su momento que la actividad administrativa y los efectos que produce son causados por la voluntad de la administración que manifiesta la voluntad de la ley, más no la del funcionario, la cual debe coincidir con aquella como requisito para la legalidad o validez de la actuación administrativa. Véase, RDJ., T. LXXXI, sección segunda (1984), p. 12. 
el cumplimiento de todas aquellas normas de orden, higiene y seguridad de la empresa, que permitan trabajar en forma normal y estable, no cabe duda que sus atribuciones deben conciliarse con las facultades de administración del titular de la misma.

Con respecto a la contratación de nuevos trabajadores, todo indica que ello es una facultad propia del empleador, que se encuentra inserta dentro de su poder de administración. De esta manera, en casos especiales, y cuando la orden de reanudación no sea obedecida, se ha estimado que nada impide que el interventor, con la autorización previa del titular de la empresa, contrate personal determinado, por el plazo necesario para la normalización, que pueda reiniciar las labores, sin perjuicio de la facultad del empleador para mantener dichos contratos ${ }^{46}$.

Al comentar esta particular norma de la Ley de Seguridad del Estado, Silva Bascuñán señaló en su oportunidad que en virtud del decreto de reanudación de faenas, las relaciones jurídicas del contrato de trabajo que se desarrollaban dentro de un carácter privado, se transforman provisionalmente en una relación de derecho público, toda vez que predomina el régimen impuesto por la autoridad sobre el que emana de la relación contractual. De esta forma, la reanudación de faenas implicaría una habilitación del legislador a la autoridad encargada de hacer efectiva todas aquellas atribuciones encaminadas a realizar su objeto específico, "que es el de forzar a las partes a la continuación del trabajo mientras el conflicto dure y hasta que sea resuelto" ${ }^{47}$.

De ahí en adelante, el problema es determinar cuáles son las obligaciones específicas que les corresponden a los sujetos involucrados. En esta dirección, parece lógico que todo lo que disponga la autoridad pública, para conseguir el propósito diseñado por el legislador, implicará una decisión de dicha autoridad y no una expresión del consentimiento de las partes involucradas en el contrato de trabajo. De tal forma que, "aunque el empleador estime ruinoso seguir las faenas durante el conflicto o el personal se rebele intimamente ante la necesidad de continuar provisionalmente trabajando en las condiciones existentes al generarse éste, una y otra voluntad deben ceder ante la voluntad nacional,

${ }^{46}$ En un sentido contrario se pronunció Oneto SesSAREgo, cit. (n. 13), p. 81, al comentar las facultades del funcionario en caso de intervención simple. A su juicio, si el interventor desea contratar uno o más trabajadores nuevos, debe dar instrucciones primeramente al empleador y será éste quien, en definitiva, llevará a cabo la contratación. Y agrega: "En la eventualidad que el interventor incorpore nuevo personal-directamente, sin dar la instrucción aludida- se encontraría en la imposibilidad de pagar ya que no tiene la administración y el empleador podría alegar que el contrato le es inoponible ya que fue celebrado por un tercero que no lo representa".

47 Cfr., Silva BasCuñán, Alejandro, Informe en derecho, en RDJ., T. LXVI, sección tercera (1969), p. 13. 
cumplida a través de la actuación del interventor designado, representante de la autoridad que debe perseguir el bien común colectivo"48. Sobre el particular, es útil tener presente la advertencia que hace Macchiavello ${ }^{49}$ en orden a que la reanudación de faenas tiene como objetivo fundamental la solución del conflicto y que en dicho sentido no existe plazo para la intervención, la cual podrá extenderse el tiempo que sea necesario para cumplir el mandato legal. En todo caso, la transitoriedad se manifiesta en el hecho que la designación perdura mientras subsistan las condiciones que motivaron el nombramiento del interventor.

No obstante, y tal como se ha señalado, las atribuciones con que cuenta el interventor no pueden significar el uso de una facultad de mando laboral absoluta y sin límites. Por el contrario, las facultades para conseguir la reanudación deben encuadrarse necesariamente dentro de aquellas gestiones indispensables para restablecer el orden interno de la empresa y que se le han encargado en virtud del decreto de nombramiento. Si algún trabajador o empleador se niega a aceptar las directrices señaladas por el interventor, entonces serán aplicables las reglas generales sobre incumplimiento laboral, sin perjuicio lógicamente de las responsabilidades eventualmente penales que concurran en cada caso particular. Así, una vez normalizada la situación, para cuyo efecto no existe plazo predeterminado, el verdadero empleador asumirá en plenitud la facultad de mando de acuerdo a la normativa vigente ${ }^{50}$. Por tanto, si bien las atribuciones que se otorgan por el artículo 38 de la Ley de Seguridad del Estado parecen sumamente amplias, esto no implicará en modo alguno la posibilidad de contratar o despedir personal de la empresa en forma independiente del empleador, situación que necesariamente se regirá de acuerdo a las normas generales. No hay que olvidar que es el conflicto el que se somete a la autoridad pública, razón por la cual el interventor deberá establecer las bases de cumplimiento laboral mínimo para que las faenas se reanuden. Si alguno de los sujetos involucrados se negare a ejecutar dichas órdenes, entones (desde la óptica laboral) el incumplimiento de la norma-

${ }^{48}$ Ibídem (n. 47), p. 14.

${ }^{49}$ Machiavello, cit. (n. 3), p. 478.

50 Ante una situación diversa, pero cuyos efectos pueden ilustrar el tema que analizamos, la Corte de Apelaciones de Santiago ha estimado que es enteramente ilegal la actuación de una autoridad administrativa estatal que pretende imponer su criterio en contra o sin contar con la voluntad de las partes que celebraron un determinado contrato de trabajo, contrato que es una ley para ellas. "Por ello, excede dicha autoridad estatal su competencia pretendiendo dejar sin efecto un nombramiento, ordenando se ponga término a un contrato del que no es parte e incluso designando a otra persona en su reemplazo". Véase, RDJ., T. LXXXVII, sección quinta (1990), p. 108. 
tiva vigente acarreará las sanciones que el propio ordenamiento ya tiene diseñadas ${ }^{51}$.

Por último, habrá que señalar que al nominarse un interventor sin facultades de administración, éste no debiera dar cuenta económica de su gestión, ya que sus atribuciones se vinculan con el restablecimiento del orden laboral, y no con el manejo directo de los bienes de la empresa. No obstante, al ser un representante de la autoridad pública, el interventor está obligado a rendir cuenta, ante ésta, de sus actos y del resultado de su gestión. El actúa como un verdadero $\mathrm{m}$ a $\mathrm{n} \mathrm{d}$ a $\mathrm{t}$ a $\mathrm{r}$ i o, $\mathrm{y}$ en tal calidad debe responder a su $\mathrm{m}$ a n d a n t e, el Presidente de la República en este caso, de las medidas adoptadas y de las consecuencias de sus acciones en calidad de interventor de la empresa paralizada ${ }^{52}$.

5 Los trabajadores deben reintegrarse en las mismas condiciones que regían al tiempo de plantearse la paralización ilegal. Envirtud de este requisito, se mantienen inalterables los derechos y obligaciones que los trabajadores tenían al momento de iniciarse la paralización. Por tanto, trabajadores y empleador tendrán las mismas facultades y atribuciones que, de acuerdo al ordenamiento jurídico vigente, les corresponden dentro de la empresa. Consecuente con esto, si durante la paralización ha existido alguna mejora en los derechos establecidos por ley con respecto a los trabajadores, éstos deben entenderse incorporados de acuerdo a las normas generales.

En lo que respecta al período no trabajado, el empleador no está obligado a pagarlo, salvo que exista un acuerdo expreso de las partes en tal sentido.

${ }^{51}$ Con algunos matices de diferencia, SilVA BASCUÑán, cit. (n. 47), p. 14, sostuvo, en relación con el primitivo artículo 38 (el cual no establecía el límite relativo a la administración que se establece en la norma actual), que el interventor gozaba de facultades de contratación y despido de trabajadores toda vez que una conclusión diversa haría imposible e ineficaz el objetivo perseguido por el legislador. Sin embargo, de conformidad con el tenor actual del artículo 38 de la Ley de Seguridad del Estado, el incumplimiento a las órdenes del interventor significa un ilícito laboral que debe ser solucionado de acuerdo a las normas establecidas en el Código del Trabajo. La tesis anterior se basa en el hecho que si bien las decisiones del interventor significan actos de autoridad obligatorios para las partes involucradas, no es menos cierto que la prohibición de efectuar actos de administración comprende la imposibilidad de despedir y contratar trabajadores, atribución que le compete solamente a la parte involucrada en la relación laboral de conformidad a la normativa vigente.

${ }^{52}$ De hecho, la jurisprudencia de la Contraloría General de la República señaló, en su momento, que el pago de las prestaciones por el desempeño de la función no podían ser de cargo "de la empresa o faena privada que se ha intervenido, ya que ello constituiría una exacción no autorizada por disposiciones legales en vigor" (Dictamen $\mathrm{N}^{\circ}$ 64.500, de 01 de septiembre de 1972). 
Ello es lógico, ya que si la remuneración es la contrapartida pecuniaria por los servicios efectivamente realizados y ellos no han existido, entonces habrá que concluir que el empleador no tiene obligación de pago de remuneraciones por el tiempo que duró la referida paralización.

\section{CONClusiones}

Los puntos que resumen las conclusiones de este trabajo, son:

1. La reforma laboral, introducida por la Ley No 20.940, ha rediseñado la figura de la reanudación de faenas durante la huelga, trasladando la facultad que antes tenía el Presidente de la República hacía la esfera del órgano jurisdiccional. Le corresponderá al juez laboral, por tanto, evaluar caso a caso la pertinencia de esta figura.

2. La reanudación de faenas, sólo procede en el caso de huelgas (o cierres temporales) que se ejercen dentro del proceso formal de negociación colectiva. De allí, que el legislador haya prefigurado esta facultad como un caso de limitación al ejercicio del derecho de huelga legal. Por tanto, el objetivo de esta figura no es facultar a la autoridad judicial para que ordene el reinicio de actividades ante cualquier tipo de paralización, sino que única y exclusivamente de aquella que se inserta dentro del proceso regular de negociación colectiva.

3. Si bien la calificación de los elementos que permiten decretar la reanudación es privativa del juez laboral, el legislador ha circunscrito la atribución dentro de un marco de causalidad objetiva. Más que el número de personas involucradas en la huelga o cierre temporal, lo relevante es el efecto que provoca la paralización, el nivel de perjuicios ocasionados y la gravedad que se deriva de los mismos. Para decretar la reanudación, en consecuencia, no basta un mero trastorno económico sino que se requiere un resultado dañoso de especial significación que atente en contra de derechos esenciales de las personas (en su acceso a bienes y servicios considerados indispensables) o para el Estado. De esta manera, la decisión judicial no puede ser meramente discrecional ya que requiere de una mínima motivación y fundamento que acredite los requisitos fundamentes de esta figura en razón de la oportunidad o duración de una huelga. Esa motivación y fundamento forman parte del derecho a defensa de los intervinientes en el proceso.

4. La facultad que el artículo 363 le otorga al juez laboral, sólo se refiere a las medidas conducentes a la reanudación de faenas. Aquí no cabe, por tanto, la aplicación de otras medidas tales como la incautación o intervención de empresa. No hay que olvidar que, será el empleador el encargado de implementar la reanudación práctica de las actividades, sin 
que ello obste a que la sentencia judicial señale las medidas que se consideran necesarias para lograr el objetivo señalado por la ley. Por lo demás, el tribunal laboral conserva la facultad de evaluar la manera en que se ha implementado la sentencia que ordenó la reanudación.

5. El artículo 363 presenta un vacío regulatorio en lo que respecta a la posibilidad de aplicar de medidas transitorias de reanudación. Debido a la demora que supone la tramitación de un procedimiento monitorio, la reanudación no puede ser inmediata y ello ciertamente que afecta el objetivo final de este tipo de normas ya que el solicitante debe esperar a que la resolución respectiva se encuentre ejecutoriada. Con todo, a nuestro entender, el tribunal laboral conserva la facultad de ordenar medidas cautelares durante la tramitación del proceso.

6. La facultad de ordenar la reanudación de faenas, no es exclusiva del Código del Trabajo. La nueva norma legal tendrá que convivir con una atribución que la Ley de Seguridad del Estado también le reconoce al Presidente de la República. No obstante, en este último caso, el Presidente puede ordenar la reanudación sólo en el evento que se trate de huelgas consideradas ilegales.

\section{BibLIOGRAFIA}

Alessandri Rodríguez, Arturo, Ilegalidad del Decreto sobre Expropiación de Salitreras, en RDJ., T. XXXVII (1940).

Alvear Urrutia, Eduardo, El Arbitraje ante la Legislación del Trabajo, en RDJ., T. XXXIX (1942).

Baylos Grau, Antonio, Derecho de huelga y servicios esenciales (2a edición, Madrid, Tecnos, 1988).

Bermúdez Soto, Jorge, Derecho Administrativo General (3a edición, Santiago, Thomson Reuter-Abeledo Perrot, 2014).

Cabezas Pereiro, Jaime, La imposición de servicios minimos, en Baylos Grau, Antonio (coordinador), Estudios sobre la huelga (1 $1^{\text {a }}$ edición Albacete, Bomarzo, 2005).

Cámara de Diputados, Informe de la Comisión de Trabajo y Seguridad Social, recaído en el proyecto de ley que moderniza el sistema de relaciones laborales, introduciendo modificaciones al Código del Trabajo. Boletín No 9835-13-1, en www.camara.cl.

Cassagne, Juan Carlos, La Huelga en los Servicios Esenciales (1a edición, Madrid, Civitas, 1993).

Cavalli Benzi, Aldo, La Reanudación de Faenas (Santiago, Memoria de Prueba, Facultad de Derecho, Pontificia Universidad Católica de Chile, 1968).

DÁvila IzQuIERDo, Oscar, Ilegalidad del decreto sobre expropiación de salitreras, en RDJ., T. XXXVII (1940).

Hernández Emparanza, Domingo, Control de constitucionalidad de actos administrativos por el Tribunal Constitucional. Precedentes Constitucionales, en Estudios Constitucionales 4 (2006), 1.

IruReta Uriarte, Pedro, Constitución y orden público laboral. Un análisis del artículo 19 
$N^{\circ} 16$ de la Constitución chilena, en Colección de Investigaciones Jurídicas 9 (Santiago, Facultad de Derecho de la Universidad Alberto Hurtado, 2006).

Jara Wolff, Octavio, La reanudación de faenas (Concepción, Memoria de Prueba. Facultad de Derecho. Universidad de Concepción, 1971).

Jeammaud, Antoine, Huelga y Servicios Esenciales en el Derecho Francés, en Revista de Treball 12 (1990).

Macchiavello Contreras, Guido, Derecho Colectivo del Trabajo (1a edición, Santiago, Editorial Jurídica de Chile, 1989).

Martin Valverde, Antonio, Rodríguez-Sañudo Gutiérrez, Fermín, y García Murcia, Joaquín, Derecho del Trabajo (24a edición, Madrid, Tecnos, 2015).

Oneto Sessarego, Antonio, Tratado General sobre Reanudación de Faenas (Santiago, Ediciones Revista Técnica del Trabajo y Previsión Social, 1971).

Palomeque López, Manuel Carlos, El derecho constitucional de huelga y su regulación en España, en Revista de la Facultad de Derecho de la Universidad Complutense de Madrid 17 (1993).

Perez Rey, Joaquín, El incumplimiento de los servicios mínimos y su revisión judicial en las huelgas que afectan a los servicios esenciales de la comunidad', en BAYLOS GRAU, Antonio (coordinador), Estudios sobre la huelga (1 ${ }^{\mathrm{a}}$ edición Albacete, Bomarzo, 2005).

Rajevic Mosler, Enrique, y Garcés Ramírez, María Fernanda, Control de legalidady procedimiento de toma de razón, en AA. VV., Un mejor Estado para Chile. Propuestas de modernización y reforma. Consorcio para la reforma del Estado (Santiago, Pontificia Universidad Católica de Chile, 2009).

Repertorio de Legislación y Jurisprudencia Chilenas, Leyes Administrativas sobre Municipalidades (2º edición, Santiago, Editorial Jurídica de Chile, 1994).

Riesco, Germán, Alcance del Artículo 547 del Código del Trabajo. Facultad de los Tribunales para rever los actos del Ejecutivo, en RDJ. T. XLIV (1947).

SaAvedra Fernández, Rubén, Discrecionalidad Administrativa (Santiago, LegalPublishing, 2011).

Silva Bascuñán, Alejandro, Informe en derecho, en RDJ., T. LXVI, sección tercera (1969).

Simpson, Bob, Los conflictos colectivos en el sector público en Gran Bretaña: el marco de relaciones legales e industriales, en Gaceta Sindical 98 (1991).

Thayer Arteaga, William, y Novoa Fuenzalida, Patricio, Manual de Derecho del Trabajo (2a edición, Santiago, Editorial Jurídica de Chile, 1987), t. I.

Vergara Baeza, Juan de Dios, y Cavalli Benzi, Aldo, Derecho de Huelga, Reanudación de Faenas, Intervención (Santiago, Ediciones López Viancos, 1972).

Vergara Blanco, Alejandro, El nuevo servicio público abierto a la competencia: de la publicatio al libre acceso. Coherencia de las viejas técnicas concesional y autorizacional, en Revista de Derecho Administrativo Económico 12 (2004).

Vergara Blanco, Alejandro, Una triada económica y jurídica: recursos naturales, bienes públicos y servicios públicos conexos para un balance de 30 años de liberalización económica en Chile (1980-2010), en FerRada Borquez, Juan Carlos (coordinador), Estudios de Derecho Público. El principio de separación de poderes. Actas de las XL Jornadas de Derecho Público 2010 (Santiago, Abeledo Perrot-Thomson Reuters, 2011). 